\title{
O USO DA MADEIRA NAS REDUÇÕES JESUÍTICO-GUARANI DO RIO GRANDE DO SUL VII - VIGA DO CORO DA IGREJA DA IGREJA DE SÃO MIGUEL ARCANJO'
}

\author{
JOSÉ NEWTON CARDOSO MARCHIORI² MARIA CRISTINA SCHULZE-HOFER ${ }^{3}$
}

\section{RESUMO}

A madeira da viga do coro da Igreja de São Miguel Arcanjo (São Miguel das Missões, Rio Grande do Sul Brasil) foi anatomicamente identificada como Tabebuia heptaphylla (Vell.) Toledo (Bignoniaceae), espécie lenhosa de notável resistência mecânica e alta durabilidade natural.

Palavras-chave: Tabebuia heptaphylla, Ipê-roxo, Anatomia da Madeira, Missões Jesuíticas, Rio Grande do Sul.

\section{SUMMARY}

[Wood utilization in the Jesuitic-Guarani Missions from Rio Grande do Sul state, Brazil. VII - Choir beam of Saint Michel Archangel's Church].

The choir beam of Saint Michel Archangel's church was anatomically identified as Tabebuia heptaphylla (Vell.) Toledo (Bignoniaceae), a wood species notable for its mechanical strength and decay resistance.

Key words: Tabebuia heptaphylla, Wood Anatomy, Jesuitic Missions, Rio Grande do Sul state.

\section{INTRODUÇÃO}

As ruínas da Igreja de São Miguel Arcanjo testemunham o apogeu da arquitetura JesuíticoGuarani em terras do atual Rio Grande do Sul. Situada no núcleo urbano de São Miguel das Missões, este reconhecido Patrimônio da $\mathrm{Hu}$ manidade compõe, juntamente com o Museu das Missões, um dos principais focos do turismo histórico-cultural no Estado.

Atribuído ao século XVIII, o fragmento remanescente da viga do coro da Igreja de São Miguel Arcanjo é o objeto do presente estudo anatômico, que visa à identificação da espécie de madeira e contribuir para o conhecimento das técnicas construtivas utilizadas neste singular período da história regional.

Recebido em 12-8-2008 e aceito para publicação em 10-11-2008.

2 Engenheiro Florestal, Dr., Professor Titular do Departamento de Ciências Florestais, Universidade Federal de Santa Maria, RS. Bolsista de Produtividade em Pesquisa, CNPQ - Brasil. balduinia@mail.ufsm.br

3 Arquiteta e Urbanista, Dra., IPHAN - Instituto do Patrimônio Histórico e Artístico Nacional. schulzehofer@gmx.de

\section{MATERIAL E MÉTODOS}

O material examinado, com sinais externos de carbonização (Figura 1C,D), foi extraído do fragmento remanescente da viga do coro da Igreja de São Miguel Arcanjo (Figura 1A,B), cuja implantação é atribuída ao século XVIII. A amostra coletada para estudo foi registrada em fichário, fotografada, acondicionada em envelope com identificação e enviada ao Laboratório de Anatomia da Madeira do Instituto Nacional de Pesquisas da Madeira, em LohbrüggeHamburgo (Alemanha), onde foram realizados os trabalhos de microtécnica e fotomicrografia. Os autores agradecem à senhora Eda John, pela colaboração nestas tarefas.

Da amostra de madeira foram preparados corpos-de-prova, orientados para a obtenção de cortes anatômicos nos planos transversal, longitudinal radial e longitudinal tangencial. Os corpos-de-prova foram fervidos em água, com vistas ao amolecimento e expulsão completa do ar, incluídos em PEG 2000 e seccionados em micrótomo de deslizamento (modelo American Optical), regulado para a obtenção de cortes anatômicos com espessura nominal de $20 \mu \mathrm{m}$. 

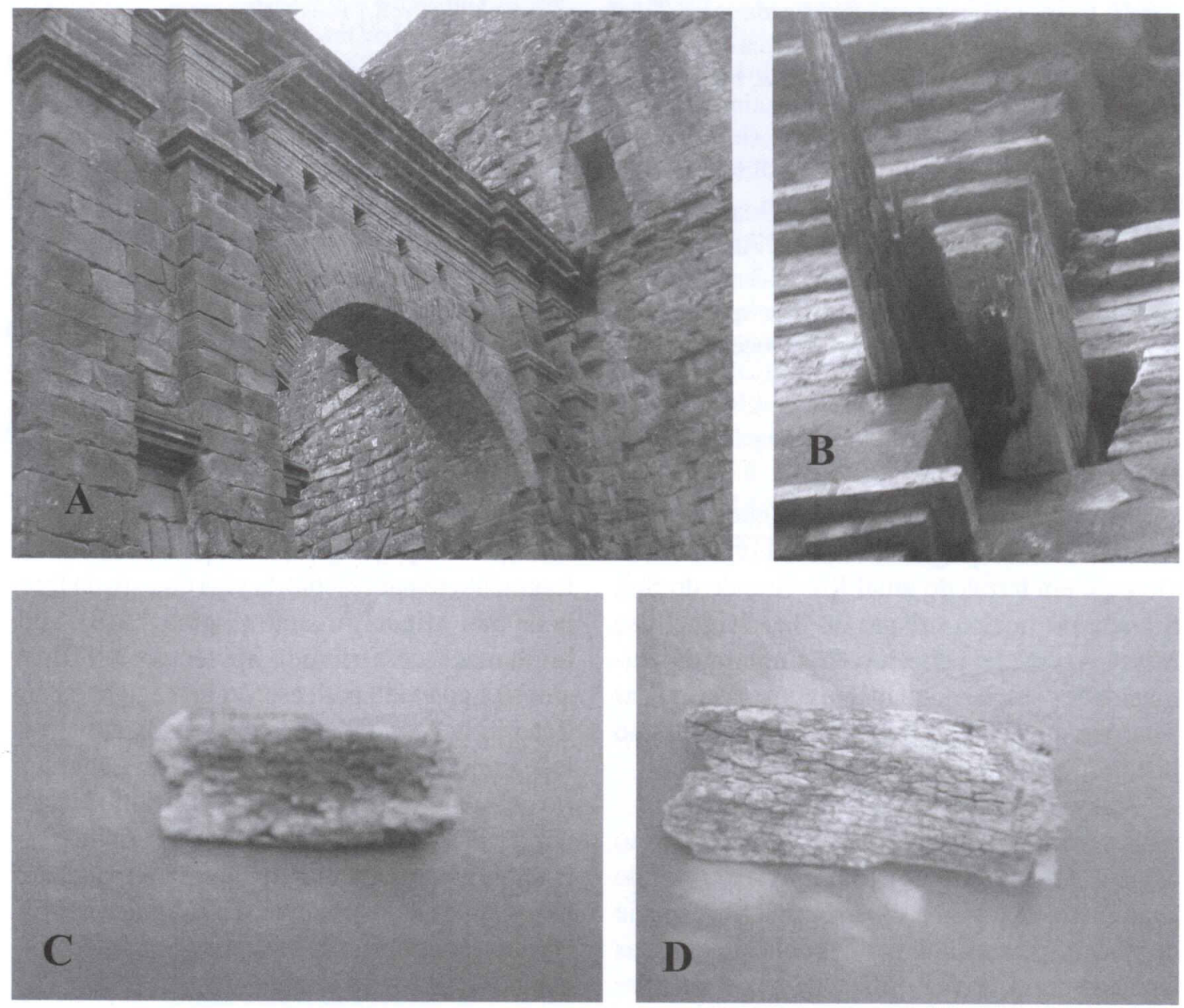

FIGURA 1 - Viga do coro da Igreja de São Miguel Arcanjo. A, B - Dois aspectos do fragmento remanescente da viga. C - Face externa da amostra coletada, com sinais de carbonização. D - Face interna da amostra. 
No caso dos cortes radiais, parte deles foi tratado com hipoclorito de sódio, com vistas a salientar eventual presença de cristais. As fotomicrografias da Figura 2, foram tomadas com câmera Olympus AX, em diferentes aumentos.

\section{DESCRIÇÃO ANATÔMICA}

Anéis de crescimento visíveis, fracamente demarcados (Figura 2A). Porosidade difusa (Figura 2A, B). Poros muito numerosos, arredondados ou ovais (Figura 2A, B) e geralmente solitários, menos comumente geminados (Figura $2 \mathrm{~A}$ ) ou em múltiplos de três. Estratificação completa, de elementos vasculares, parênquima axial, raios e fibras (Figura 2E, F).

Elementos vasculares retilíneos (Figura 2CF), com placas de perfuração simples e abundante conteúdo amarelado na cavidade celular (Figura 2A-F). Pontoações intervasculares alternas, não ornamentadas, de 12 a $14 \mu \mathrm{m}$ de diâmetro, com aréola circular e abertura lenticular inclusa. Espessamentos espiralados, ausentes.

Parênquima paratraqueal escasso a pouco confluente (Figura 23A, B). Séries parenquimáticas, geralmente compostas de duas células.

Raios homogêneos, com freqüência de 5-10/ mm (Figura 2E), compostos inteiramente de células procumbentes (Figura 2D). Raios com menos de 10 células de altura e geralmente trisseriados em plano longitudinal tangencial, menos comumente uni e multisseriados (Figura 2E, F).

Fibras libriformes de paredes espessas a muito espessas (Figura 2B).

\section{ANÁLISE ANATÔMICA E DISCUSSÃO}

Os raios relativamente estreitos e baixos, as pontoações intervasculares não ornamentadas, a porosidade difusa e a ausência de espessamentos espiralados em vasos, remetem a amostra à família Bignoniaceae, segundo cha- ve dicotômica para madeiras americanas de estrutura estratificada (Record, 1943).

O parênquima paratraqueal escasso, com pouca confluência, a porosidade difusa, a abundância de conteúdo amarelado nos vasos e os raios finos, com 3-4 (raro mais) células de largura, inserem a amostra no "grupo Lapacho" do gênero Tabebuia (Record \& Hess, 1940). Composto de numerosas espécies - e ampla distribuição geográfica -, o referido grupo distingue-se das demais seções de Tabebuia pela cor castanho-esverdeada da madeira, bem como pela presença de abundantes depósitos amarelados (Lapachol) em vasos do cerne (Record \& Hess, 1943).

O exame comparativo dos três cortes anatômicos com exemplares representados no Laminário do Departamento de Ciências Florestais da Universidade Federal de Santa Maria, permite a identificação da madeira investigada como Tabebuia heptaphylla (Vell.) Toledo, espécie botânica conhecida popularmente como ipê-roxo no Rio Grande do Sul, com base na presença de raios relativamente finos e parênquima vasicêntrico incompleto, tendente a confluente, sem formar, todavia, faixas concêntricas.

A utilização do ipê em construções missioneiras tem respaldo em relatos de cronistas do período jesuítico, notadamente de Cardiel e Sepp, bem como em obras de Félix de Azara, militar e naturalista espanhol que visitou as extintas Missões no século XVIII.

Em "Las Misiones del Paraguay", Cardiel (1989) informa que para "pilares o horcones" usava-se preferencialmente a madeira de "árboles muy altos y gruesos llamados Tajivos", grafia da época para Tají ou Taji-hü, vozes guaranis correspondentes ao ipê ou Lapacho, conforme diversos dicionários e outras obras de referência (Dimitri, 2000; Guasch, 1991; Peralta \& Osuna, 1950). A respeito do termo "Ipê", cabe salientar que em língua tupi (Igpê) a palavra também alude à casca da árvore (CUNHA, 1989). 

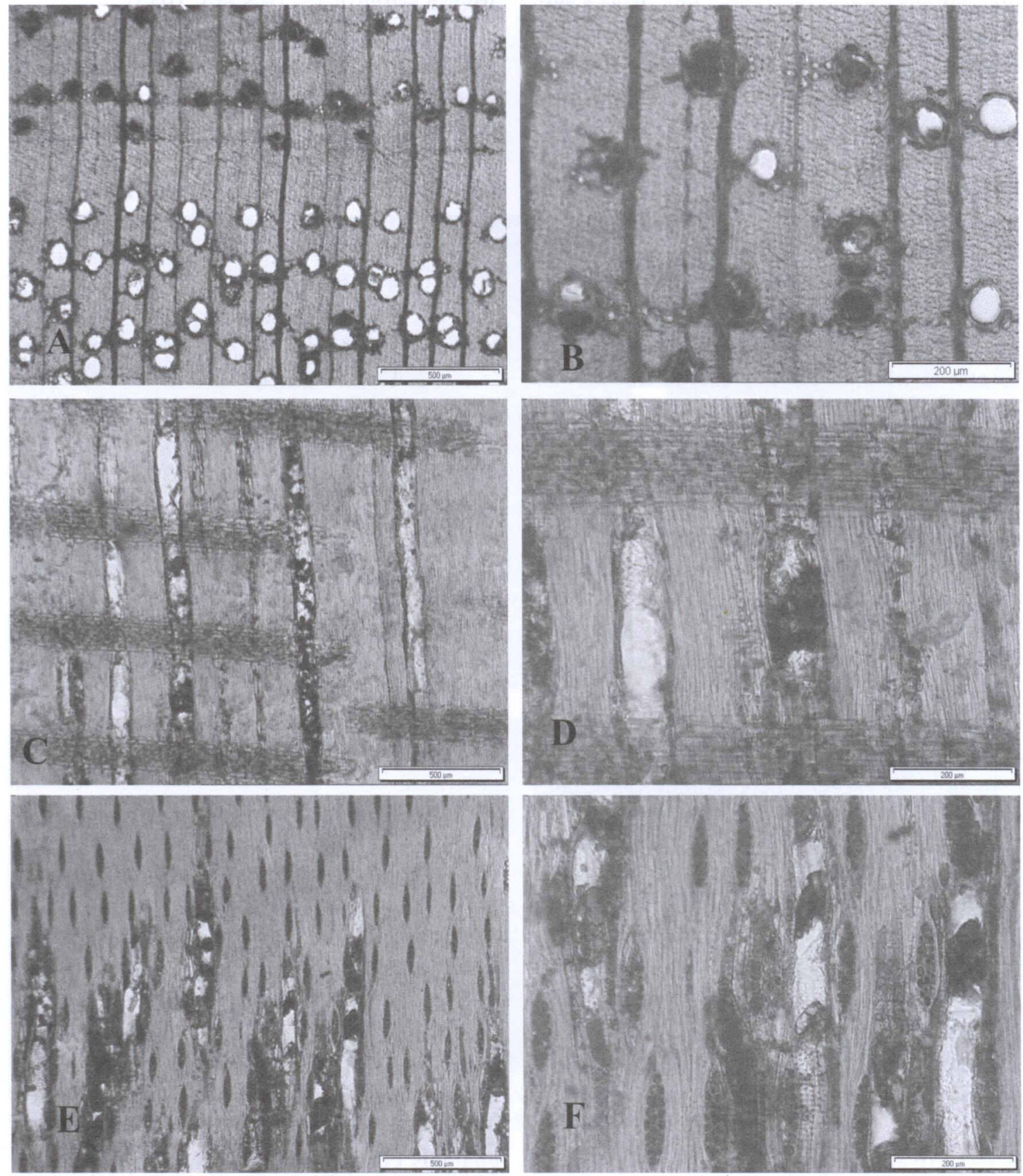

FIGURA 2 - Fotomicrografias do fragmento de madeira da viga do coro da Igreja de São Miguel Arcanjo. A - Anel de crescimento fracamente demarcado, porosidade difusa, poros muito numerosos, arredondados ou ovais, e parênquima paratraqueal escasso, pouco confluente, em seção transversal. B - Fibras de paredes espessas a muito espessas e parênquima paratraqueal escasso a pouco confluente, em seção transversal. C - Linhas vasculares retilíneas, com abundante conteúdo, e raios homogêneos, compostos inteiramente de células procumbentes, em seção longitudinal radial. D - Mesmos aspectos da imagem anterior, com maior aumento. E - Estratificação completa e vasos com abundante conteúdo, em seção longitudinal tangencial. F - Mesmos aspectos da imagem anterior, com maior aumento. 
Na mesma linha de Cardiel, o Padre Antônio Sepp (1972) informa que "para las cumbreras de las Iglesias o casa del padre" usava-se madeira de "Tuxifo", uma clara variante de Tajý-hü, grafia moderna correspondente a ipê, na língua guarani.

O militar, viajante e polígrafo Felix de Azara (1847) registrou, por sua vez, que o Lapacho era uma das madeiras preferidas para tabuados, vigas, tesouras e outros fins construtivos, por causa de sua notável durabilidade natural.

Abundante na região missioneira, o ipê-roxo é árvore de grande porte, com troncos retos e diâmetro considerável em indivíduos adultos, produtora de madeira notável por sua durabilidade natural e elevada resistência mecânica. $\mathrm{O}$ uso do ipê, comprovado no presente estudo anatômico, demonstra que os construtores jesuítas conheciam perfeitamente a matéria-prima utilizada, pois souberam escolher, na flora regional, a espécie mais adequada para uso em peças de grandes dimensões, caso da viga do coro, na Igreja de São Miguel Arcanjo.

\section{REFERÊNCIAS BIBLIOGRÁFICAS}

AZARA, F. de. Descripcion é Historia del Paraguay y del Río de la Plata. Madrid: Imprenta de Sanchiz, 1847. v. 1.346 p.
CARDIEL, J. Las Misiones del Paraguay. Madrid: Historia 16, 1989. 204 p.

CUNHA, A. G. da. Dicionário histórico das palavras portuguesas de origem Tupi. São Paulo: Melhoramentos : Editora da Universidade de São Paulo, 1989. 357 p.

DIMITRI, M. J. El nuevo libro del arbol: especies forestales de la Argentina oriental. Buenos Aires: El Ateneo, 2000. v. 2.124 p.

GUASCH, A., ORTIZ, D. Diccionario CastellanoGuaraní Guaraní-Castellano: Sintacticofraseologico-ideologico. Asunción: Centro de Estudios Paraguayos "Antonio Guasch" (CEPAG), 1991. 826 p.

PERALTA, A. J., OSUNA, T. Diccionario GuaraniEspanõl y Español-Guarani. Buenos Aires: Editorial Tupã, 1950. 427 p.

RECORD, S. J. Woods of storied structure. Tropical Woods, New Haven, n. 76, p. 32-47, 1943.

RECORD, S. J., HESS, R. W. American timbers of the family Bignoniaceae. Tropical Woods, New Haven, n. 63, p. 9-38, 1940.

RECORD, S. J., HESS, R. W. Timbers of the New World. New Haven: Yale University Press, 1943. $640 \mathrm{p}$.

SEPP, P. A. Viagens às Missões Jesuíticas e trabalhos apostólicos. São Paulo: Livraria Martins / Editora da Universidade de São Paulo, 1972. 206 p. 